Viso - Cadernos de estética aplicada Revista eletrônica de estética

ISSN 1981-4062

$N^{\circ} 19$, jul-dez/2016

http://www.revistaviso.com.br/

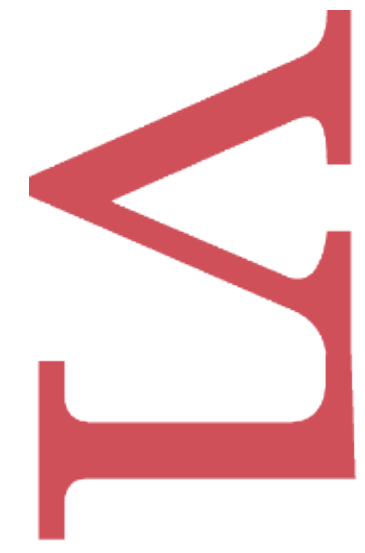

htp.//www.revistaviso.com.br/

\title{
Tudo sendo dado: sobre imagens readymades, espelhos e triangulações \\ Mariana Lage
}




\section{RESUMO}

Tudo sendo dado: sobre imagens readymades, espelhos e triangulações

O presente artigo trabalha com a perspectiva da arte como espelho transformador das consciências, como defendido por Arthur Danto, em diálogo com a análise de Jacques Leenhardt sobre a obra "Etant Donnés", de Marcel Duchamp, a fim de pensar, em última instância, se a própria realidade poderia funcionar como um espelho, uma vez que habitamos um momento histórico em que a distinção entre arte e realidade perdeu sua evidência e em que estamos submersos em reflexos (selfies e black mirrors) e imagens clichês (imagens readymades) em excesso.

Palavras-chave: imagem readymade - arte contemporânea - Arthur Danto - Jacques Leenhardt - espelho

\section{ABSTRACT}

\section{All Being Given: On Readymade Images, Mirrors and Triangulations}

The present article works with Arthur Danto's perspective on art as a improving mirror for conscience changes in dialogue with Jacques Leenhardt's analysis of "Etant Donnés", Marcel Duchamp last work, in order to think if it's possible for reality itself to be a mirror, since we inhabit a world in which the distinction between art and reality it's not clearly evident, a world submersed in glimmers (selfies and black mirrors) and cliché images (readymade images).

Keywords: readymade image - contemporary art - Arthur Danto - Jacques Leenhardt mirror 


\section{LAGE, M. "Tudo sendo dado: sobre imagens readymades, espelhos e triangulações". In: Viso: Cadernos de estética aplicada, v. X, n. 19 (jul-dez/2016), pp. 162-177.}

DOI: 10.22409/1981-4062/v19i/238

Aprovado: 14.10.2016. Publicado: 28.12.2016.

(C) 2016 Mariana Lage. Esse documento é distribuído nos termos da licença Creative Commons Atribuição-NãoComercial 4.0 Internacional (CC-BY-NC), que permite, exceto para fins comerciais, copiar e redistribuir o material em qualquer formato ou meio, bem como remixá-lo, transformá-lo ou criar a partir dele, desde que seja dado o devido crédito e indicada a licença sob a qual ele foi originalmente publicado.

Licença: http://creativecommons.org/licenses/by-nc/4.0/deed.pt BR

Accepted: 14.10.2016. Published: 28.12.2016.

(C) 2016 Mariana Lage. This document is distributed under the terms of a Creative Commons Attribution-NonCommercial 4.0 International license (CC-BY-NC) which allows, except for commercial purposes, to copy and redistribute the material in any medium or format and to remix, transform, and build upon the material, provided the original work is properly cited and states its license.

License: http://creativecommons.org/licenses/by-nc/4.0/ 
Este ensaio retoma o raciocínio principal do artigo "Arte como espelho", de Pedro Süssekind, e o provoca a pensar o paradigma da arte como espelho em nova chave, partindo de referencias próximas ao texto de Süssekind, como Arthur Danto e Jean-Paul Sartre, embora extrapolando-o na direção de um tema caro a Danto, isto é, a indiscernibilidade entre obras de arte e meras coisas reais. Mantendo como problema referencial a indistinção entre arte e vida, propõe-se pensar o paradigma do espelho a partir das imagens readymades de Marcel Duchamp e a análise proposta por Jacques Leenhardt para a obra "Etant donnés". A pergunta basilar deste texto é: se a arte chegou em um momento em que ela é de fato um fragmento da realidade, ou em que entre ela e a realidade não haveria distinções (ao menos visivelmente marcantes), poderia a realidade funcionar como a arte e nos espelhar, oferecendo-nos uma face desconhecida de nós mesmos? Na dissolução das fronteiras entre arte e realidade, entre imagens refletidas e superfícies refletoras, como, onde ou quando engajar a percepção que qualifica algo como obra de arte?

\section{Reconhecendo superfícies refletoras}

No artigo "Arte como espelho", Pedro Süssekind trabalha múltiplos espelhamentos, nomeadamente: entre o pintor Lucian Freud e o crítico Martin Gayford, entre a pintura de Freud e seu modelo representado, entre o livro de Gayford e a pintura de Freud, entre a peça de Hamlet e a consciência do rei Cláudio, entre Narciso e a superfície do rio, entre Arthur Danto e a representação de Peleu na pintura do maneirista Joachim Wtewael, entre o torso arcaico de Apolo e o poeta Rainer Maria Rilke, entre obras de arte e meras coisas banais. Podemos notar, contudo, que pelo menos um desses espelhamentos é trifásico: entre o espectador, o livro de Gayford e o quadro de Freud. Nas palavras de Süssekind: "Com isso, o observador pode reconhecer no olhar do modelo a imagem do pintor formada pelo livro". ${ }^{1}$ No olhar retratado de Gayford, o espectador veria o pintor Lucian Freud, refletido pelo livro, exterior à cena; isto é, anterior ao encontro entre espectador e pintura num determinado tempo e espaço. O espectador ideal - que vê o quadro e conhece de antemão a circunstância de sua produção - se coloca entre duas contemplações recíprocas: o olhar do pintor para seu modelo e o olhar do modelo que também retrata, em escrita, o seu pintor. Se a obra de arte é um espelho, as obras homônimas de Lucian Freud e de Martin Gayford, Homem com cachecol azul, espelham a si mesmas. Poderíamos conjecturar que, diante de dois espelhos, o espectador funcionaria como um ponto de triangulação que impossibilitaria que os espelhos 
refletissem a si mesmos em cascata, gerando assim a imagem do infinito. Desta forma, como ponto de triangulação, o espectador ideal tem uma perspectiva duplamente intensificada das circunstâncias envolvidas na feitura do quadro e de seus agentes.

Pensando ainda no "antiquíssimo problema da mimese artística", a questão, lembra Süssekind, que remonta a Danto que resgata o Sócrates de Platão, é saber se o retrato é um mero reflexo, uma cópia sem valor ou importância, ou se é, por outro lado, uma via de acesso ao que, sem a imitação ou o reflexo, não poderia ser conhecido de outro modo. O romancista Julian Barnes, que também escreveu sobre a relação entre o crítico e o pintor, opina que, mais do que retratar, trata-se de "intensificar" o referencial até que a pintura pudesse substituir o original. E Süssekind menciona que Barnes lembra que Freud teria dito que os retratos não deveriam se parecer com as pessoas. "A pintura é a pessoa". O reflexo seria assim mais real do que o real, pois, nesse processo de intensificação, o retratado "é ele [mesmo], mas só que mais ainda" ${ }^{2}$, como se o retrato revelasse mais do que o referencial pudesse transparecer em dada circunstância individual. Estaríamos diante de uma síntese viva, para além da carne, que, parcial e contingente, se desfaz, apodrece.

Nesse jogo refratário, uma imagem conformada não seria um mero reflexo ou cópia de segunda mão, mas um dispositivo disponível para o exercício do autoconhecimento, também disponível por meio do conhecimento do outro. Nesse sentido, a fim de argumentar a favor da arte como espelho transformador (da consciência), Danto referencia, em A transfiguração do lugar comum, a complexidade epistemológica envolvida no jogo de espelhos (de consciências) presente na peça do personagem Hamlet, Morte de Gonzaga, em oposição a uma epistemologia mais simples exemplificada por Narciso e a superfície do rio e, ainda, pela cena em que o Sócrates de Platão caracteriza a arte como mero reflexo, como se a ação do artista fosse meramente a de segurar um espelho e apontá-lo para qualquer direção e, ao fazê-lo, produzir imagens refletidas da realidade.

Embora Narciso não se encontrasse diante de uma obra de arte, Danto toma seu exemplo para tratar da qualidade cognitiva das imagens refletidas. Narciso, que não se conhecia, teria morrido de súbito autoconhecimento "exatamente como previra Tirésias". ${ }^{3}$ No entanto, foi a ignorância de si que o levou a enamorar-se por sua própria imagem e, numa sede de mergulhar no olhar do outro que o mirava, a se afogar. Há de se destacar, contudo, que ele se enamora pela imagem refletida (si mesmo), mas não enxerga a superfície refletora (o rio). Ele enxerga apenas o reflexo, que é tomado por real, carnal, vivo (um outro). Se no exemplo de Narciso há uma relação direta entre o referencial e seu reflexo, e a superfície refletora é como que apagada da relação, para apenas se relevar como relevante após o afogamento e a morte de Narciso, nos termos de Sartre, mencionados por Danto, há uma triangulação entre ver e ser visto. O voyeur, o sujeito que observa um objeto ou um sujeito, é também um objeto de observação de um terceiro elemento, exterior à cena observada. De acordo com Sartre, o "para-si" ocorre quando a 
consciência reflete a si mesma como consciente de si (o referencial humano e o espelho), enquanto o "para-o-outro" se dá na percepção da consciência em ser objeto para outra consciência. Se "não há nada na estrutura interna do ser para-si, assim compreendido, que o leve a conceber a si mesmo como um objeto", no "para-o-outro", o ser "participa do modo degradado de ser das coisas de que sempre se distinguiu", resume Danto. ${ }^{4}$

As considerações de Danto sobre Narciso e Sartre mostram que o espelhamento da peça dentro da peça de Hamlet são mais complexas do que o espelhamento entre Narciso e a superfície do rio. São mais complexas pois, cito Süssekind, "envolvem ao mesmo tempo o reconhecimento de que a encenação é um espelhamento de seus próprios atos e, por outro lado, a consciência de que um outro, o príncipe Hamlet, também tem consciência daqueles atos, a ponto de reencená-los". ${ }^{5}$ Como sintetiza Danto, no momento culminante, Cláudio "percebe que Hamlet sabe que Cláudio sabe que Hamlet sabe das torpes verdades". ${ }^{6}$ Num complexo jogo de espelhos, o rei Cláudio é o espectador privilegiado de Hamlet, é para ele que se revela "o reflexo" daquilo difícil ou impossível de se ver. Nessa perspectiva, Cláudio é o espectador-rei. Poderíamos dizer que ele é o único que detém a chave da interpretação, do porquê da toda a encenação de Morte de Gonzaga. É para ele, pois, que se encena, para Ihe dizer: "eu sei", mas, não somente isso, trata-se de evidenciar: "eu sei que você sabe que eu sei". Um complexo jogo de reflexos que tem a peça como ponto de triangulação e como evidência de uma superfície refletora entre o real e a imagem refletida.

No recurso de Danto a Narciso e Sartre, há Hamlet e sua peça dentro da peça de Shakespeare. Hamlet é o paradigma do espelho do artista que reflete mais do que podemos ver. Para Danto, Hamlet, mais do que Sócrates, é o exemplo referencial da arte como espelho que transforma a consciência, pois, por meio de obras de arte, podemos ver algo que, de outro modo, não podemos ver, conhecer ou reconhecer: nós mesmos. Como lembra Danto em sua epígrafe, retomada por Süssekind, embora a rainha não veja nada, ela vê tudo o que há para ser visto. Ela vê e não vê o fantasma do ausente.

\section{A imagem refletida e (algumas) triangulações}

Gostaria de conjecturar, então, que toda relação do espectador com uma obra é uma relação de triangulação - não sendo portanto uma exclusividade do espectador ideal das obras homônimas Homem com cachecol azul, de Lucian Freud e de Martin Gayford. Consideremos que a obra de arte é obviamente obra de um artista. Por mais que ela seja idêntica a um objeto real ou a uma cena banal do cotidiano, ela ainda é resultado de escolha ou de um fazer artístico. Enquanto a relação entre Narciso e sua imagem é direta, isto é, o referencial e seu reflexo, a relação de espelhamento entre a consciência de Hamlet e a consciência do rei Cláudio é interposta por uma peça, que dá então o reconhecimento de um saber recíproco: "eu sei que você sabe que eu sei". No 
paradigma da arte como espelho como exemplificada por Sócrates de Platão, o artista segura o espelho, (e se posso dizer mais uma obviedade) ele não é o espelho (ou a superfície do rio de Narciso). Ele é ainda um fazedor, que, poderíamos dizer, cria realidade dentro da realidade (no entendimento de Platão, reflexos a partir de reflexos), assim como, paralelamente, o príncipe Hamlet cria uma peça dentro da peça de Shakespeare. Enquanto, na concepção da mimese platônica, a obra de arte é uma cópia de segunda mão das formas imutáveis (por isso, vale lembrar, serem apenas reflexos), no caso de Hamlet há um mise-en-abyme paralelo: a encenação Morte de Gonzaga é uma peça escrita por um personagem de Shakespeare - e a encenação dentro da encenação continuaria evidenciando, assim, o paradigma da obra de arte como espelho. A diferença é que, para Platão, esses reflexos que são as obras de arte não seriam mais que sombras de sombras, enquanto na interpretação de Süssekind, seguindo Danto, Sartre e Shakespeare, tais reflexos nos conduzem a uma melhor compreensão de nós mesmos. O que o argumento de Danto demonstra é que, para a obra de arte funcionar como espelho transformador da consciência, é preciso reconhecer o jogo refratário entre consciências que ela coloca em causa. Se a obra de arte não é mero reflexo, embora se coloque como superfície refletora e evidencie sua função como reflexão, o espetador, nesse ideal da arte como espelho, estaria mais afinado com a postura de Cláudio (de ver na obra o reflexo de um saber recíproco, ou ainda, do reconhecimento da consciência de ser objeto para outra consciência, o "para-o-outro" sartriano) do que de Narciso (que estaria preso numa atitude não só de não saber de si, mas sobretudo de não saber distinguir a imagem refletida da superfície refletora). Desta forma, entre a realidade e a arte que reflete a realidade, o espectador se situa como ponto de triangulação, como vértice externo à tensão de um par de polaridades: ele se coloca entre o referencial e a imagem refletida, e, também, entre a imagem conformada e a presença (da sombra) do artista na obra. Ele se vê na obra e, tal como o poeta Rainer Maria Rilke, pode se sentir visto, observado, tanto pela obra quanto por aquele que a conformou. "Pois ali ponto não há que não te mire". ${ }^{7}$ Apesar de estar diante de um objeto (obra de arte), este objeto não é uma superfície oca ou translúcida, i.e., reflete aquele que a fez e, similarmente, reflete aquele que a contempla.

A questão persistente de Danto, vale lembrar, é a respeito da indiscernibilidade entre arte e realidade, ou ainda, o que fazer da filosofia e da crítica de arte quando as distinções entre arte e vida são não visivelmente notáveis e - admite Danto em alguns momentos irrelevantes. Minha pergunta simples ao filósofo estadunidense (e, por conseguinte, a Süssekind) é: se a arte chegou a um momento em que ela é de fato um fragmento da realidade, em que, dizendo com Danto ${ }^{8}$, a fronteira entre arte e realidade deixou de existir, ou ainda, em que a fronteira entre arte e realidade não tem nem mesmo a espessura de um espelho, onde estariam as superfícies refletoras?

No artigo "The Gap between Art and Life", de 2009, Danto disserta a respeito dos readymades de Duchamp como ato que dissolveu as fronteiras entre arte e realidade, inaugurando assim a era do pluralismo radical; ${ }^{9}$ Traduzindo para os termos da nossa 
discussão (embora Danto não referencie dessa forma), o readymade conteria assim o espelho duplo: ele é o referencial e sua repetição. Com os readymades, escreve Danto, "tudo se tornou possível como arte, o que é o mesmo que dizer que as fronteiras [entre arte e realidade] estão em todo lugar". ${ }^{10}$ No referido artigo, o filósofo retoma a ideia de pensar a história da arte como história de fronteiras. Referindo-se a Hegel e à Revolução Francesa, Danto resume a situação histórica da arte na década de 1960 como aquela que realiza, analogamente no âmbito das artes, o estado democrático. Se, em seu paralelismo, na monarquia artística haveria uma fronteira ("a conquista da aparência"), e na oligarquia, algumas fronteiras (o que foi representado pelo modernismo e a época dos manifestos), na democracia, isto é, na arte contemporânea, as fronteiras estariam em todos os lugares. Se a fronteira está por toda parte, argumenta Danto, ela não só se tornou invisível como efetivamente deixou de existir. "Sabia-se de antemão que qualquer coisa poderia ser obra de arte, de forma que se tornou inútil perguntar se isso ou aquilo poderia ser [obra de arte]". ${ }^{11}$ Essa ideia de "pluralismo radical" como ausência de fronteiras aparece de forma semelhante em diversos momentos em Danto, em especial, ao final do artigo "O fim da arte", publicado em 1987, quando retoma Marx e afirma que "na era do pluralismo" não importa muito o que se faz. Contudo, ao invés da ausência de fronteiras, Danto fala em ausência de direcionamento, e afirma, para destacar mais uma vez a tese do fim da narratividade histórica da arte, que "a liberdade termina em sua própria realização. ${ }^{12}$ Algumas linhas antes, havia escrito: "você pode ser um abstracionista de manhã, um fotorrealista à tarde, um minimalista mínimo à noitinha. $\mathrm{Ou}$ você pode cortar bonecas de papel ou fazer o que mais the aprouver". ${ }^{13}$ Seríamos levados a concluir que não faria mais sentido falar em liberdade quando ela se torna realidade concreta para todos, assim como não faria sentido continuar distinguindo arte e realidade quando as distinções entre elas deixam de existir. Contudo, como nosso cotidiano continua demonstrando, a liberdade não chegou ao seu término e tampouco as fronteiras deixaram efetivamente de existir (apesar dos anseios dos artistas contraculturais da década de 1960 e 1970). Ainda, apesar de, em meados dos anos 1980, Danto ter imaginado ${ }^{14}$ (ironicamente?) o desaparecimento das instituições do mundo da arte, ele continuou fomentando o seu não desaparecimento.

Em "The Gap between Art and Life", Danto insiste mais uma vez que, se as diferenças entre arte e vida não são mais visivelmente notáveis, seria papel do crítico de arte estabelecer o significado das obras e torná-lo público. A tarefa do crítico é tornar visível aquilo que, sem ele, não poderíamos ver - seguindo o raciocínio da arte como espelho: nós mesmos (embora Danto também demonstre que é papel da crítica revelar a autoconsciência filosófica da arte contemporânea ou, talvez ainda, a distinção - tornada irrelevante na contemporaneidade - entre arte e vida). Utilizando como exemplo a obra "A Few Centimeters above Sea Level", de Shahab Fotouhi e Neda Razavipour, que havia visto em 2005 numa galeria em Tribeca, Danto afirma, talvez de forma (nada) surpreendente, que sem a explicação do artista, ou do galerista-curador, a obra seria nada mais do que "uma banheira, algumas garrafas, alguns arames, uma porção de líquido preto e alguns peixes". ${ }^{15}$ Se não nos dão a chave de interpretação da obra, nós, o 
público que não conhecemos nosso Ovídio, não sabemos olhá-la, isto é, somos incapazes de nos comportarmos como o espectador-rei Cláudio. Se conseguimos ver, vemos a obra como um amontoado de coisas que nada reflete, "um mero entretenimento palaciano"16, como teriam visto os demais espectadores da peça de Hamlet. Numa época de pluralismo radical, o crítico faria assim, seguindo o raciocínio de Danto, a intermediação (ou a triangulação) entre o público e a obra, nos possibilitando ver aquilo que, sem ele, não poderíamos ver. Na concepção de Danto, que o exemplo acima torna claro, o que faz a distinção entre arte e realidade é o significado intencionado pelo artista e exposto pelo galerista, curador ou crítico. Num outro texto, "Crítica de arte após o fim da arte", Danto é ainda mais literal e explícito:

O crítico é aquele que tem de recuperar qual efeito a arte tem sobre o espectador qual significado o artista quis trazer - e, em seguida, como este significado deve ser lido no objeto no qual ele foi incorporado. Eu vejo a minha tarefa como mediação entre o artista e o espectador, ajudando os espectadores a apreender o que foi intencionado. Pode ter havido tempos em que críticos não precisavam interpretar a arte para os espectadores, mas da maneira como a história da arte se desenvolveu o crítico é cada vez mais requisitado a explicar ao espectador o que está sendo visto. ${ }^{17}$

Deste modo, se a fronteira está em todos os lugares (que é o mesmo que dizer que ela não existe), não seria forçoso, portanto, pensar que, de acordo com Danto, o crítico funcionaria como espelho, daria o recorte, forneceria o frame por meio do qual podemos ver ou o que deveríamos olhar? Num mundo de indistinção entre arte e vida, ou, em outra chave, num cotidiano inundado em reflexos e imagens clichês como o nosso, o crítico seria aquele que engaja a consciência naquilo que realmente importa. E, afirma Danto, "engajar a consciência é o sentido último da superação do hiato entre arte e vida". ${ }^{18}$ Num período histórico de dispersão e liberdade, em que "uma direção é tão boa quanto outra"19, o crítico daria a direção do engajamento: do olhar, da consciência, da percepção. E qual faceta de nós mesmos, qual rio de Narciso o crítico poderia revelar no contexto de excesso imagético e de aparente indistinção entre arte e vida? Usando Danto contra Danto, gostaria de imaginar que o crítico contemporâneo nos relevaria que a realidade assim como a arte não são superfícies transparentes, isto é, são formas com significado, que são "a respeito de algo", que o significado é estabelecido/lido histórica e culturalmente (mas, sobretudo, a partir de uma experiência individual), que as superfícies não transparentes e cheias de significado dizem muito de nós mesmos e que têm um potencial transformador da consciência humana. No entanto, apesar da minha imaginação e desejo, para Danto, tais características seriam exclusivas da arte e seriam justamente o que distingue arte de realidade; isto é, que obras de arte são significados incorporados; (i) são sobre alguma coisa e (ii) incorporam um significado.

Os pássaros que bicaram as uvas de Zêuxis, assim como o personagem Testadura de Danto $^{20}$, que se deita nas camas de Oldenburg e de Rauschenberg, tomam a arte pela realidade, mas, numa reversão de um problema antigo, e se tomássemos a realidade por arte? Retomando uma pergunta anterior deixada em aberto: em um contexto de 
dispersão e indistinções, poderia a realidade mesma ser como a arte e, nos espelhando, oferecer-nos uma faceta desconhecida de nós mesmos? Seria assim possível, ao contrário de Narciso, reconhecermos o real como superfície refletora e, na mesma medida, reconhecermos a imagem refletida sem, no entanto, nos perdermos cegamente nela? Entre outras palavras, quando temos experiências estéticas com a realidade, ou, por exemplo, quando nos encontramos diante de uma imagem readymade, haveria ali reflexo que nos permitiria ver mais do que vemos, mais do que há ali - algo que nos mire e nos convoque a uma percepção transformadora, fazendo-nos um convite a mudarmos de vida, como foi a experiência de Rilke diante do torso arcaico de Apolo? Ou, ao contrário, mesmo na ausência de superfícies refletoras, necessitaríamos do crítico a nos apontar para onde olhar e o que ver, em caso ainda pior, a nos ajudar a reconhecer a intencionalidade do artista $^{21}$ inscrita numa obra (aparentemente) indistinta da realidade?

\section{A ausência de espelhos e as imagens readymades}

Sobre ausência de superfícies refletoras, é curioso lembrar a peça de Sartre intitulada Entre quatro paredes ${ }^{22}$ (no original, Huis Clos, de 1944). Nela, três pessoas, desconhecidas entre si, morrem e chegam ao inferno: uma espécie de quarto de hotel em que são obrigadas a conviver pelo resto da eternidade. No quarto, onde a luz está sempre acesa, não há janelas nem espelhos; elas estão eternamente sujeitas ao olhar do outro. Embora não haja espelhos enquanto superfícies cristalinas e refletoras, os três habitantes do inferno refletem uns aos outros, refletem quem são: Garcin, um escritor covarde, Estelle, a fútil amante assassina, Inês, a lésbica sádica. Apesar dos esforços em se esconderem, não podem fugir de si mesmos nem dos Outros, não podem mirar a si mesmos, tampouco podem dormir - pois são destituídos de pálpebras. O inferno é estar sempre disposto ao olhar do outro, em um mundo sem descanso ou isolamento. Nessas circunstâncias, o que veem de si é o que o outro reflete, sem superfícies intermediárias ou sem subterfúgios de obras de arte, como no caso do rei Cláudio e de Hamlet. Se, para Sartre, o espelho é o símbolo do movimento da consciência que volta para si mesma (o "para-si"), já que somente através dele o eu tem acesso à própria imagem, no inferno, a consciência se vê presa do jogo de reflexos do "para-o-outro". Assim, embora não sejam superfícies refletoras, os três prisioneiros "funcionam" entre si como espelhos. Desta forma, colocando a pergunta inicial em outros termos: mesmo na ausência de espelhos como superfícies refletoras, poderia a realidade - ou o outro de nós - nos refletir? Porém, ao contrário da peça de Sartre, nos refletir de forma não opressora, mas intensificada e transformadora?

Gostaria de abordar, a seguir, a ausência de espelhos a partir das imagens clichês ou das imagens readymades trazendo a perspectiva de Jacques Leenhardt. Devido à concisão do espaço, gostaria de mencionar de relance uma crença que sustenta o argumento deste artigo: a ideia, cara à hermenêutica fenomenológica - ao menos à la Gadamerr $^{23}$, Jauss ${ }^{24}$ e Zumthor ${ }^{25}$-, de que é a experiência estética o que transforma, ou 
que atualiza, algo de potencialmente estético ou artístico em efetivamente estético ou artístico. O que sugiro é: no lugar de uma estética da representação, uma estética do performativo. Se, diante do problema posto pela arte contemporânea de indiscernibilidade em relação à realidade, a saída de Danto é por meio da interpretação histórica, ontológica e essencialista, para Leenhardt, (consoante com a hermenêutica fenomenológica mais recente) a saída é pela estética, pela percepção, pelo despertar de uma nova sensibilidade, pela mobilização da capacidade de olhar. Sobre a transição de uma estética da representação para uma estética do performativo ${ }^{26}$, ao invés de ainda se ocupar filosoficamente com as características do objeto obra de arte (que possibilitam diferenciá-lo da realidade e lhe instituir um significado), trata-se de abrir caminho para a compreensão (e a vivência) do estético, artístico ou poético como um acontecimento, suscetível e contingente ao encontro e à copresença entre autor, público e obra.

No artigo "Marcel Duchamp: crítica da razão visual", Leenhardt ${ }^{27}$ encontra nas obras do artista francês a realização da autoconsciência da arte. Embora Leenhardt entenda que os readymades são a evidência da arte em um estágio não só de autoconsciência, mas, sobretudo, de questionamento de seus meios e suas definições, sua conclusão, contudo, diferentemente da de Danto, não atribuiu à crítica - na figura do especialista que desvela um sentido oculto para o público - qualquer papel de destaque. ${ }^{28} \mathrm{~A}$ própria obra provocaria no espectador uma tarefa crítica e reflexiva. Nos termos deste artigo, a própria obra colocaria em evidência tanto a imagem refletida quanto a superfície refletora.

No referido artigo, Leenhardt analisa a intervenção do readymade "no âmago da cultura" e argumenta que, para o objeto industrial ter sido possível como obra de arte, duas transformações históricas deveriam ter ocorrido: a) a industrialização das reproduções imagéticas ${ }^{29}$, a ampliação dos seus modos de produção e a subsequente transformação da percepção e dos modos de conhecimentos, e b) a emergência de um juízo estético amplificado, diferente do mundo dos especialistas. Uma esfera alargada do juízo de gosto, na concepção de Leenhardt, permitiria que, de fato, o público participasse e interferisse no debate sobre o que é ou não obra de arte e como a percebemos, como se "do próprio âmago do público" pudesse surgir "o juízo e a legitimação da arte. Desde então a arte é o que o público reconhece como arte". ${ }^{30}$ Se o público tem ou não autonomia e liberdade para participar e determinar essa "legitimação da arte" é uma outra pergunta -diga-se de passagem que, se recorremos a Danto, a resposta seria: ainda dependemos do crítico. Contudo, Leenhardt utiliza essa ideia de amplificação da esfera do juízo de gosto para justificar as mudanças históricas que permitiram que objetos tão banais como os readymades de Duchamp adentrassem nas considerações e debates sobre a arte. ${ }^{31} \mathrm{~A}$ (suposta ou almejada) ausência de critérios de julgamento assim como a (suposta ou almejada) democratização do gosto fariam com que o juízo se apresentasse, mais do que como um sentido estável ou unívoco, como "uma expectativa de sentido, uma promessa de sentido, o que Duchamp chamava 'a forma impossível do possível"'. ${ }^{32} \mathrm{E}$ assim, afirma adiante: "Em ausência de jurisprudência, a arte só pode 
propor, como ainda dizia Duchamp, a 'figuração de um possível', expressão na qual devemos entender a noção de possível como 'um corrosivo químico (tipo vitríolo) queimando toda estética ou calística'”. ${ }^{33}$ Assim, num contexto de alargamento de critérios, em que qualquer direção é tão boa quanto a outra, a obra não daria uma chave de interpretação, mas apenas aludiria a um provável, a "uma figuração de um possível" (na abordagem próxima da estética do performativo, uma forma estética provisória, contingente ao encontro e às circunstâncias de copresenças entre obra, autor e público, contudo, sempre inaugural).

Quanto à industrialização do cotidiano, teria sido preciso que as imagens se tornassem excessivas, que fossem produzidas em larga escala, que habitassem diversos espaços da arena pública, que a arte se tornasse autônoma na figura da instituição museu, e que ainda, por fim, a reprodução imagética de obras de arte se transformasse em prática corriqueira para que, nas palavras de Leenhardt, se abrisse "uma nova história da percepção da arte". "Sabemos que Duchamp inventou o readymade. Esquecemos, porém, que ele também inventou a imagem readymade, quer dizer, a apresentação de uma imagem impressa como uma obra de arte". ${ }^{34}$ Seguindo o raciocínio, a imagem readymade, assim como o próprio objeto readymade, revelariam o contexto de saturação e de liberdade (corrosiva, sem critérios), "a situação paradigmática do olhador" que, imerso em "torrentes infinitas de imagens reproduzidas tecnicamente", antes de ver uma determinada obra ou ter uma experiência estética já a conhece (poderíamos dizer, como se diz comumente, "de vista"). ${ }^{35}$

Com sua última obra "Etant donnés", descoberta seis meses após sua morte, Duchamp teria, de acordo com Leenhardt, ressimbolizado a imagem banal readymade. Se, para o biógrafo e crítico Calvin Tomkins ${ }^{36}$, a instalação teria insistido na completa separação entre as esferas de arte e vida devido à sua estranheza e ao seu distanciamento em relação ao todo da obra duchampiana, para Leenhardt trata-se do oposto: da exibição sarcástica da imagetização exacerbada da vida, evidenciando que, num mundo onde tudo está dado, trata-se agora de apenas olhar - como sugeriu certa vez John Cage, que, por sua vez, aprendeu bem com Duchamp: "Você só tem de ouvir inesperadamente, da mesma forma que quando você fica resfriado tudo que você faz é inesperadamente espirrar". ${ }^{37}$

Passo, portanto, à análise que Leenhardt faz da última obra de Duchamp. "Etant donnés" é o título da obra sobre a qual o artista francês trabalhou em segredo durante os últimos 20 anos de sua vida, entre 1946 e 1966. Trata-se de uma instalação como um peep show, em que o espectador é colocado na posição de voyeur e, ao olhar pelo buraco numa porta de madeira, vê uma cena bucólica, com um corpo feminino deitado nu, de pernas abertas, sobre a relva, tendo imagens impressas como pano de fundo. Sabemos que o artista trabalhou intensamente para reproduzir o aspecto de pele a esse corpo modelado a partir da escultora brasileira Maria Martins. No entanto, a instalação traz apenas imagens clichês hiperrealistas. Na leitura de Leenhardt, Duchamp chama nossa 
atenção para um mundo inundado de fabricações imagéticas frequentemente exageradas, embora exacerbadamente convencionais, em que a imagem é já a repetição de algo anteriormente dado e visto. Com "Etant donnés", Duchamp teria mostrado que, num mundo imerso em reflexos e clichês, a realidade é mais que uma sucessão de imagens readymades, seria uma máquina de olhar. Como sintetiza o autor: "tudo sendo dado, a arte viverá da atividade dos olhadores". ${ }^{38} \mathrm{Na}$ seguinte passagem, Leenhardt se aproxima de uma perspectiva afinada com uma estética do performativo e uma estética fenomenológica.

Por esse dispositivo, Duchamp acentua a ideia de que a visão não tira o seu sentido daquilo que é mostrado, mas daquele que olha. O 'olhador' faz a obra, no segredo que Ihe é imposto pelo dispositivo. Se ainda assim haverá arte amanhã, todas as imagens sendo dadas, isto se dará no segredo de uma relação nova e individual, a qual se arrancará das imagens infinitamente socializadas de que nosso mundo industrial nos impregna. ${ }^{39}$

Desta forma, "tudo sendo dado", poderíamos ser convidados a pensar que a observação aberta, atenciosa e meditativa ${ }^{40}$, aquela que possibilita a experiência estética, recorta o real e dá a forma estética a um fragmento do vivido. A pergunta "é arte ou não é arte?" deixaria de importar, já que se trata de uma experiência e/ou uma percepção estética se quiser, transformadora. E aqui é curioso perceber que Danto inúmeras vezes chegue a ser literal ao dizer que, se o hiato entre arte e vida é suprimido, as definições de arte então deixam de importar, embora sua filosofia da arte tenha sido uma filosofia preocupada, ainda, com a ontologia da obra. Isso justifica o fato de, apesar de dizer que a pergunta "é arte ou não é arte" é irrelevante após 1960, ele considera de extrema relevância o papel da crítica em estabelecer o significado da obra e torná-lo público, de dizer por que ela é uma obra, isto é, por que ela incorpora bem seu significado. Se conseguíssemos realmente pensar (ou viver) em uma realidade contemporânea de indistinção entre arte e vida, então, num mundo de imagens readymades ou reflexos clichês, não seria o nomeado "mundo da arte" aquilo que conformaria (chancelaria) a distinção entre meras coisas reais e obras de arte, mas a performance da percepção numa explicitação redundante da concepção de $Z_{\text {umthor }}{ }^{41}$-, seria o engajamento do público no ato da experiência estética ("o segredo de uma relação nova e individual"²). É o ato da percepção estética que dá a forma, improvável, evanescente, provisória e contingente a cada encontro - algo nada estanque, unívoco ou suscetível a uma visão privilegiada, sentada em um "castelo, no topo do mundo, aproveitando as boas coisas da vida". ${ }^{43}$ Numa sociedade de black mirrors e selfies, em que tudo é reflexo, e em que todas as imagens estão dadas, a forma estética viveria da atividade dos percebedores. A atividade dos percebedores, convoca Leenhardt, deve por si só ser crítica, "um empreendimento crítico".

Contudo, se ainda queremos pensar com Danto e o seu paradigma do espelho, haveria a possibilidade de o referido (pra não dizer consagrado) "mundo da arte" poder funcionar como frame, como ponto de triangulação entre o real e o espectador, uma moldura para 
intensificar nossas percepções do sensível, que nos mostre mais do que vemos, que matize, tonalize, tonifique, para que então possamos ver, dentre um emaranhado de reflexos e poluição imagética, aquilo que importa, nos dizeres de Danto, aquilo que "engaja a consciência". Mas esse "mundo da arte" certamente não poderia ser, de acordo com o raciocínio que se desenvolve aqui, o mesmo da trinca de C's atuais, críticos, colecionadores e curadores a alimentar um mercado especulativo financeiro; ou, tampouco, um mundo da arte ainda preocupado com estabilização de sentido e apresentação ao público da intencionalidade do autor, ou socialização de filosofias da arte realizadas (ou somente exemplificadas) por meio de obras de arte. Seria mais próximo, se é possível aqui imaginar possíveis, a um mundo do estético, mas afinado com a afinação da percepção e do sensível (e essa discussão já é trabalho para outra pesquisa).

Por último, portanto, meu exemplo readymade arte-vida em Belém, ou experiência estética no cotidiano, ou ainda, a realidade como espelho. Em Belém, a realidade às vezes é tão crua e absurda, ou melhor, o enquadramento circunstancial de espaço e tempo em que se habita num aqui e agora contingente pode parecer tão absurdamente conformado em termos críticos e potentes que somos levados a nos questionar se não estaríamos de fato diante de uma obra de arte de um terceiro, exterior à cena. Mas olhamos de novo e parece apenas um fragmento de realidade, indistinto, alheio, um momento passageiro, displicente, deslocado em sua banalidade absurda potente. Um exemplo: em frente ao Mercado Ver-o-Peso, há uma edificação do século XIX, um pavilhão metálico verde em art nouveau, conhecido como Mercado da Carne, que, como o nome sugere, abriga a parte de açougue do maior mercado a céu aberto da América Latina. Minha imagem readymade é um enquadramento do Box do Pedro. Pedro, o açougueiro, é de se presumir, gosta de carnes, das de vacas e de mulheres. Na vitrine do seu box, ao lado dos cortes do dia, de vermelho sangue, é possível ver duas imagens clichês envelhecidas e amareladas em papel jornal do tipo "revista masculina". Trata-se de carne magra, branca, seminua, ostentando calcinhas e sutiãs.

Por fim, uma última pergunta: diante de imagens readymades, seria a obra de arte o fantasma do ausente?

\section{* Mariana Lage atua como pós-doutoranda no Departamento de Filosofia da UFPA (CAPES/PNPD).}

${ }^{1}$ SÜSSEKIND, P. "Arte como espelho". Trabalho apresentado no VIII Encontro do GT de Estética da ANPOF, na UFOP, Ouro Preto, 2016, p. 4.

2 BARNES, J. Keeping an Eye Open, p. 265, apud SÜSSEKIND, P. Op. cit, p.1.

${ }^{3}$ DANTO, A. A transfiguração do lugar comum. Tradução de Vera Pereira. São Paulo: Cosac Naify, 2005, p. 44.

${ }^{4}$ Ibidem, p. 45. 
${ }^{5}$ SÜSSEKIND, P. Op. cit., p. 7.

${ }^{6}$ DANTO, A. Op. cit., p. 46.

${ }^{7}$ RILKE, R. M. apud SÜSSEKIND, P. Op. cit., p. 14.

8 DANTO, A. "The Gap between Art and Life". In: JACOB, M. J.; BAAS, J. Learning Mind: Experience into Art. Berkeley: University of California, 2009, p. 20.

9 "Around the time of World War I he [Duchamp/ML] established that there need be no outward difference between artworks and ordinary things. When one thinks about it, this sounds quite close to the goal of overcoming the difference between appearance and reality, the frontier implied by the 'conquer of appearances' - the defining goal of traditional art" (Ibidem, p. 20; tradução da autora).

10 "Everything was now possible as art, which is what I meant by saying that the frontier is everywhere" (Ibidem, p. 20; tradução da autora)

11 "One knew in advance that anything could be a work of art, so it was pointless to ask whether this or that could be" (Ibidem, p. 21; tradução da autora)

12 Idem. "O fim da arte". In: O descredenciamento filosófico da arte. Tradução de Rodrigo Duarte. Belo Horizonte: Autêntica, 2014, p. 152.

${ }^{13}$ Ibidem, p. 151.

14 "A liberdade termina em sua própria realização. Uma arte subserviente sempre esteve conosco. As instituições do mundo da arte - galeristas, colecionadores, exposições, jornalismo -, que são baseadas na história e, portanto, registram o que é novo, desaparecerão pouco a pouco" (Ibidem, p. 152).

${ }^{15}$ Idem. "The Gap between Art and Life". Op. cit., p. 27.

${ }^{16}$ Idem. A transfiguração do lugar comum. Op. cit., p. 46.

17 Idem. "Crítica de arte após o fim da arte". In: Revista de Estética e Semiótica, v. 3, n. 1 (jan-jun/2013), pp. 82-98, , aqui p. 97 (grifos nossos).

18 "Engaging consciousness is ultimately the means of overcoming the gap between art and life". (Idem. "The Gap between Art and Life". Op. cit., p. 27; tradução da autora).

${ }^{19}$ Idem. "O fim da arte". Op. cit., p. 152.

${ }^{20}$ Idem. "O mundo da arte". Tradução de Rodrigo Duarte. In: Artefilosofia, n. 1 (jul/2006), pp. 13-25, aqui pp. 16-17.

${ }^{21}$ Nos artigos "Patologias no sistema da literatura" e "O autor como máscara", Hans Ulrich Gumbrecht demonstra que a proliferação dos prefácios, com suas necessidades de estabilizar o sentido e evidenciar a intenção do autor, é um fenômeno marcadamente moderno, surgido com a invenção da imprensa e a proliferação do livro impresso como veículo do sentido (retirando o corpo da primazia que gozava em época previamente anterior), ou seja, algo que tem origem em torno de meados do século XV. Cf. GUMBRECHT, H. U. "Patologias no sistema da literatura". In: Corpo e forma: ensaios para uma crítica não-hermenêutica. Rio de Janeiro: EDUERJ, 1998; e "O autor como máscara”. In: Modernização dos sentidos. Tradução de Lawrence F. Pereira. São Paulo: Ed. 34, 1998.

22 SARTRE, J.-P. Entre quatro paredes. Rio de Janeiro: Civilização Brasileira, 2011.

${ }^{23}$ GADAMER, H. G. Verdade e método. Tradução de Flávio Paulo Meuer. Petrópolis: Editora Vozes, 1997.

24 JAUSS, H. R. Aesthetic Experience and Literary Hermeneutics. Tradução de Michael Shaw. Minneapolis: University of Minnesota, 1982. 
${ }^{25}$ ZUMTHOR, P. Performance, recepção, leitura. Tradução de Jerusa Ferreira Pires. São Paulo: Cosac Naify, 2007.

${ }^{26}$ Sobre essa noção cf. FISCHER-LICHTE, E. The Transformative Power of Performance: A New Aesthetics. Tradução de Saskya Iris Jain. London; New York: Routledge, 2008.

${ }^{27}$ LEENHARDT, J. "Duchamp: crítica da razão visual". In: NOVAES, A. Artepensamento. São Paulo: Companhia das Letras, 1994.

28 "Temos de admitir que esta irrupção do que por analogia poderemos chamar a democracia no juízo artístico semeou, e ainda semeia, uma inenarrável confusão no mundo da arte. É, como temos visto, o fim dos critérios. O que virão a ser os especialistas do juízo estético, os críticos? Como irão trabalhar os diretores de museu? Eles seriam sensatos em esperar que o público, que a história, tenha emitido o seu oráculo. Mas quem aceitará admitir não saber?" (Ibidem, p. 346).

29 Industrialização ocorrida durante o século XIX, em especial, com o desenvolvimento da imprensa, com as impressoras a vapor e as rotativas, com a invenção da fotografia e a cromolitografia.

${ }^{30}$ Ibidem, p. 345.

${ }^{31}$ Sabe-se que a "aceitação" dos readymades de Duchamp foi algo que ocorreu bem posterior à época de sua produção (das década de 1910 a 1940), mais precisamente em torno do início da década de 1960, por intermédio de uma nova geração de artistas, como John Cage, Robert Rauschenberg, Richard Hamilton e Jasper Johns.

32 Ibidem, p. 346.

${ }^{33}$ Ibidem, p. 347.

${ }^{34}$ Ibidem, p. 344.

${ }^{35}$ Ibidem, p. 348.

${ }^{36}$ TOMKINS, C. The Bride and the Bachelors. New York: Gagosian Gallery, 2013, p. 11.

${ }^{37}$ CAGE, J. De segunda a um ano. Tradução de Rogério Duprat, revista por Augusto de Campos. São Paulo: Hucitec, 1985, pp. 100-101.

${ }^{38}$ LEENHARDT, J. Op. cit., p. 348.

${ }^{39}$ Ibidem, p. 349 (grifo nosso).

${ }^{40}$ Me baseio aqui no pensar meditativo de Heidegger e seu conceito de Gelassenheit, presente, em especial em Serenidade e Country Path Conversations. Desenvolvi mais sobre o caráter performativo da percepção estética, diante de um possível contexto de indistinção entre arte e vida, na tese "Tônus da presença: experiência estética como jogo, quietude e contingência". Cf. HEIDEGGER, M. Serenidade. Tradução Maria Madalena Andrade. Lisboa: Instituto Piaget, 2001; Country Path Conversations. Tradução de Bret W. Davis. Bloomington: Indiana University, 2010; MIRANDA, M. L. Tônus da presença: experiência estética como jogo, quietude e contingência. Tese (Doutorado em Filosofia). Programa de Pós-Graduação em Filosofia, Universidade Federal de Minas Gerais, Belo Horizonte, 2015.

${ }^{41}$ Cf. ZUMTHOR, P. Op. cit.; ZUMTHOR, P. Introdução à poesia oral. Tradução de Sônia Queiroz e Jerusa Ferreira Belo Horizonte: UFMG, 2010.

${ }^{42}$ LEENHARDT, J. Op. cit., p. 349.

${ }^{43}$ DANTO, A. O abuso da beleza, p. 165, apud SÜSSEKIND, P. Op. cit., p. 12. 